\title{
SAUDADE E NOSTALGIA: CONFIGURAÇÕES PASSIONAIS DA FALTA NO SHOW ROSA DOS VENTOS, DE MARIA BETHÂNIA
}

\author{
SAUDADE AND NOSTALGIA: \\ PASSIONATE CONFIGURATIONS OF MISSING IN MARIA BETHÂNIA'S CONCERT \\ ROSA DOS VENTOS
}

\author{
Renato Forin Junior ${ }^{1}$ \\ UEL - Universidade Estadual de Londrina
}

\begin{abstract}
RESUMO: Saudade e nostalgia são paixões que, por vezes, apresentam um caráter indistinto. O presente artigo busca, na abordagem semiótica, ferramentas que esclareçam as configurações passionais destes sentimentos tão difundidos na língua portuguesa e ainda pouco estudados pela teoria da significação. A partir de definições dos lexemas, da investigação etimológica e, finalmente, de análises das modalizações semióticas, o trabalho traça as principais diferenças entre os afetos ligados à falta. Tais estados de alma surgem, em geral, em um sujeito privado de um objeto-valor, o que produz um estado disfórico. O discurso patemizado reflete, então, os impasses modais de um "querer estar conjunto", apesar da impossibilidade. A nostalgia caracteriza-se como uma modalidade específica de saudade. Para uma compreensão mais prática destes limites conceituais - além de citar uma série de textos literários e jornalísticos - o artigo evoca trechos do espetáculo Rosa dos ventos, estrelado por Maria Bethânia em 1971. Em plena ditadura militar, o show cantava a saudade dos exilados políticos por meio de um roteiro composto por poesias e canções.
\end{abstract}

PALAVRAS-CHAVE: Saudade; nostalgia; Maria Bethânia; Rosa dos ventos; canção.

\begin{abstract}
Saudade and nostalgia are passions that sometimes demonstrate an indistinct character. This paper seeks to find, in semiotic approach, tools that clarify the passionate configurations of these feelings so widespread in the Portuguese language and less studied by theory of meaning. From the definitions of lexemes, etymological research and finally the semiotic modalization analysis, this work establishes the main differences between these two words that describe the feelings of missing. Such soul conditions appear; in general, in individuals deprived from having an object-value, which produces dysphoric state. The passionate speech reflects, then, modals impasses of a "desire to be together", in spite of the impossibility. Nostalgia is characterized as a specific form of saudade. For a more practical understanding of these conceptual boundaries - besides mentioning a variety of literary and journalistic texts - the article evokes parts of the Rosa dos ventos concert, starring Maria Bethânia in 1971. During the military dictatorship, the feeling of saudade of exiled politicians was sung in the concert through a script composed with poems and songs.
\end{abstract}

\footnotetext{
${ }^{1}$ Mestrando no Programa de Pós-graduação em Letras (Estudos Literários) da Universidade Estadual de Londrina (PR). O pesquisador é bolsista da CAPES. Contato: renatoforin @ gmail.com.
} 
KEYWORDS: Saudade; nostalgia; Maria Bethânia; Rosa dos ventos; song.

\section{INTRODUÇÃO}

Diz-se, corriqueiramente, que saudade é palavra que só existe, com sentido rigoroso, na língua portuguesa. Se a assertiva é verdadeira, faz-se urgente e necessária uma investigação que adentre os meandros desse sentimento para a compreensão de suas singularidades a partir de uma ferramenta que considere as significações pelo viés da cultura. A semiótica apresenta-se, aqui, como instrumento útil para a compreensão das idiossincrasias dessa paixão, bem como das diferenças e semelhanças com outro lexema de parecido teor: a nostalgia.

Pelo menos desde a década de 80 , a semiótica de linha francesa deixou de debruçar-se apenas sobre as ações dos sujeitos, configuradas pelas modalidades do "fazer", expandindo ainda mais os labirintos da enunciação no nível narrativo - passou a considerar também os seus "estados de alma". Os sujeitos começaram a ser entendidos como entidades altamente modalizáveis, capazes de se transformarem ao longo de seus percursos, além de estenderem as relações, antes restritas a objetos, a outros sujeitos num imbricado jogo de manipulações ("fazer-fazer").

É só a partir dessa abertura que se tornam possíveis as reflexões deste artigo no âmbito da semiótica. $\mathrm{O}$ que apresentamos aqui são reflexões acerca da natureza das paixões relacionadas à falta e à ausência. Buscam-se os conceitos, definições e etimologias para a compreensão das semelhanças e diferenças lexicais entre saudade e nostalgia dentro da língua portuguesa. A partir destes limites, passamos para um aprofundamento vertical sobre as modalizações que geram, em nível narrativo, as duas paixões.

Desde a investigação do léxico até o desvelamento das estruturas semióticas que configuram saudade e nostalgia, recorremos a uma série de exemplos na literatura e no jornalismo, o que torna mais clara a natureza das paixões em jogo. Assim, citamos alguns excertos de escritores brasileiros, bem como trechos de entrevistas e ensaios, como exemplificação das paixões. Isso porque essas estruturas nunca ocorrem de modo independente, pois "captar os efeitos de sentido globalmente como 'cheiro' dos dispositivos semionarrativos postos em discurso é reconhecer, de certa maneira, que as paixões não são propriedades exclusivas dos sujeitos, mas propriedades do discurso inteiro" (FONTANILLE, GREIMAS, 1991, p.21).

Especificamente, para delinear a diferença entre as configurações patêmicas, aplicamos a teoria em dois momentos do show Rosa dos ventos, estrelado por Maria Bethânia no ano de 1971. O contexto da ditadura militar e o exílio de Caetano Veloso e Gilberto Gil levaram a intérprete a construir, junto de Fauzi Arap, um roteiro de textos e canções onde se mostram, com especial relevo, os sentimentos de saudade e nostalgia.

A análise inicial é da letra da canção Pai Grande, integrante do Primeiro Ato do show; em seguida, investiga-se a conjugação das letras de Minha História (Chico Buarque) e Lembranças (Benil Santos e Raul Sampaio), que figuram na segunda parte.

Pela natureza lírica do primeiro texto, a análise reside mais no nível discursivo, por meio da exploração de temas e figuras, além da extração de oposições semânticas imanentes no texto. Já o segundo texto de canção, de caráter épico, permite incursões nos percursos narrativos. 


\section{Saudade e nostalgia - distâncias e aproximações}

Saudade e nostalgia são paixões que parecem apresentar intersecções sêmicas. Sempre empregados para designar o estado do sujeito que se vê privado de um objeto-valor do qual se recorda com apreço, esses sentimentos, por vezes, aparecem com caráter indistinto. As fronteiras conceituais precisam ser, entretanto, destacadas para que se evitem confusões terminológicas na construção do discurso, ou para melhor se compreender os significados nas instâncias mais abstratas da enunciação.

As definições dos lexemas são o ponto de partida para o estudo das paixões. De acordo com Greimas (1983, p. 225, tradução nossa), "sabe-se que os lexemas aparecem frequentemente como condensações que recobrem, por pouco que explicite, estruturas discursivas e narrativas muito complexas". ${ }^{2}$ Para Fiorin (2007b, p.14), "na língua, as paixões recobrem-se umas às outras e, muitas vezes, é difícil distingui-las entre si". O autor assevera a busca de conceitos de fundo cultural - proposta por Greimas - e sugere a decomposição das unidades sintagmáticas autônomas, o que propicia a obtenção de sentidos a partir das potencialidades do texto e auxilia na previsibilidade das análises discursivas.

Numa consulta a dicionários da língua portuguesa, percebe-se uma associação quase sinonímica entre saudade e nostalgia. Ferreira (2004) define a primeira como "lembrança nostálgica e, ao mesmo tempo, suave, de pessoas ou coisas distantes ou extintas, acompanhada do desejo de tornar a vê-las ou possuí-las; nostalgia", ou ainda como "pesar pela ausência de alguém que nos é querido".

Já Houaiss (2009) amplia as causas possíveis da saudade ao considerá-la um "sentimento melancólico devido ao afastamento de uma pessoa, uma coisa ou um lugar, ou à ausência de experiências prazerosas já vividas". O mesmo autor acrescenta que o termo pode ser utilizado, no plural, para designar "cumprimentos amigáveis de quem sente ou diz sentir a falta de outrem".

O recorrente uso da nostalgia para referir-se a esse afeto leva-nos a depreender que, em sentido genérico e amplo, os dois lexemas podem ser considerados sinônimos. Há, entretanto, uma série de especificidades que precisam ser mencionadas.

A primeira delas diz respeito à intensidade melancólica investida na nostalgia, que parece atenuar-se na saudade (mais "suave"). Michaelis chega a abordar a primeira pelo viés patológico, definindo-a como "doença ou tristeza profunda, causada pelas saudades da pátria". Houaiss (2009) fala em "distúrbios comportamentais e/ou sintomas somáticos provocados pelo afastamento do país natal, do seio da família", ou seja, o sentimento da falta passa de um estado passional, para um desvio com consequências físicas e psicológicas. $\mathrm{O}$ autor acrescenta: "saudade de algo, de um estado, de uma forma de existência que se deixou de ter; desejo de voltar ao passado".

A primeira diferença, portanto, está na consequência do afeto: a nostalgia está associada a um desalento intenso e patológico, enquanto a saudade pode manifestar-se de maneira mais tênue e de forma menos pejorativa, como uma lembrança afável.

Fica evidente, a partir dessas definições de dicionário, uma outra distinção importante - a nostalgia refere-se mais especificamente à ausência de um contexto integral, ou seja, o objeto-valor é um lugar e/ou um tempo perdidos, que persistem na memória do sujeito e cujas lembranças provocam pesar pela impossibilidade ou dificuldade de regresso. É o sentimento de um indivíduo degredado, exilado de suas instâncias primordiais, a exemplo

\footnotetext{
2 "Il est notoire que les lexèmes se présentent souvent comme des condensations recouvrant, pour peu qu'on les explicite, des structures discursives e narratives fort complexes".
} 
da terra natal ou da infância já passada. Ferreira (2004) define a nostalgia como "melancolia produzida no exilado pelas saudades da pátria".

A segunda diferença liga-se, assim, à causa da paixão: enquanto a saudade é mais genérica e pode originar-se pela ausência de uma pessoa ou coisa, a nostalgia é provocada por uma conjectura de elementos que caracterizam uma existência ou uma vida passada intangível e/ou um presente distante, eis o motivo pelo qual é empregada quando se aborda o exílio ou a expatriação.

Pode-se, assim, utilizar o lexema saudade como designativo para qualquer tipo de falta que provoque um ávido desejo de "voltar a ver/ter/viver". Já a nostalgia estaria relacionada especificamente à ausência saudosa (e dorida) de todo um contexto a que se não tem mais acesso. A nostalgia, em suma, seria uma modalidade de saudade, enquanto nem toda saudade poderia ser chamada nostalgia.

Carlos Drummond de Andrade explica a generalidade da primeira quando diz que "sentimos saudades de momentos de vida e momentos de pessoas" (ANDRADE, 1987, p.144).

Clarice Lispector, ao descrever os sentimentos de Macabéa e Olímpico, par antirromântico de A hora da estrela, ajuda a compreender a configuração do outro afeto: "eles esqueciam o amargor da infância porque esta, já que passou, é sempre acre-doce e dá até nostalgia" (LISPECTOR, 2006, p.56). A nostalgia, aqui, mostra-se como o acesso sinestésico a este contexto de passado - lembrança que nunca poderá ser inteiramente doce.

Pode-se estabelecer um paralelo da nostalgia expressa no excerto de Clarice com um trecho de Esaú e Jacó, em que Machado de Assis descreve as idas e vindas da saudade, sentimento cuja configuração despe-se de maiores afetações lânguidas, ou do peso da desventura (como acontece na outra paixão), para dulcificar-se:

Como é que se matam saudades não é coisa que se explique de um modo claro. Para elas não há ferro nem fogo, corda nem veneno, e todavia as saudades expiram, para a ressurreição, alguma vez antes do terceiro dia. Há quem creia que, ainda mortas, são doces, mais que doces. (ASSIS, 2002, p.107).

A saudade é, sem dúvida, o lexema mais recorrente quando da discursivização do sentimento da falta. Como percebemos nos exemplos acima, esta paixão, por seu sentido genérico, pode ser utilizada em diferentes âmbitos e mesmo para se referir a condições menos disfóricas. Isso parece dar-se não só no Brasil, mas também na pátria mãe da língua. $\mathrm{O}$ escritor português Fernando Assis Pacheco critica os que preterem a nostalgia:

Uso pouco a palavra saudade, em favor da palavra nostalgia. O conceito de nostalgia é muito mais dorido que o de saudade. A saudade é bonita, dá para o Carlos do Carmo e a Amália cantarem. A nostalgia pressupõe amigos que morrem; mulheres amadas que desaparecem; filhas que crescem e já não são como eram em pequeninas; eu que já não tenho a destreza dos vinte anos, já não jogo à bola, já tenho digestões difíceis. A nostalgia não está devidamente contemplada na poesia portuguesa. À força de tentarmos fazêla passar por uma categoria filosófica menor chamada saudade, esquecemonos de que o tempo foge e ninguém o agarra. (PACHECO, apud SILVESTRE, 2008).

Temos aqui o reforço das especificidades da nostalgia, deflagrada pelas lembranças de experiências passadas e, geralmente, impossíveis de serem novamente Disponível em: http://seer.fclar.unesp.br/casa 
vivenciadas, como as pessoas e circunstâncias de quando se tem "vinte anos". Decorre dela uma série de outras paixões, como a angústia, a tristeza e a melancolia, oriundas da constatação existencial de que o tempo passa e arrasta com ele as sensações e os fatos vividos. O mundo, assim, é para o nostálgico um objeto sempre antigo e intangível justamente por seu eterno renovar-se.

Um último exemplo para que se compreenda a diferença entre essas duas categorias patêmicas vem de Paulo Freire. No ano de 1984, na ocasião de uma entrevista que concedeu à Revista Lua Nova, o célebre educador falou a respeito do período em que esteve exilado e a forma com a qual os sentimentos de saudade e nostalgia manifestam-se naqueles que estão longe da pátria:

Nós não podíamos permitir que essa relação, entre nós, fosse mediada pela nostalgia e virasse razão de enfermidade. Ela devia, pelo contrário, ser motivo de saúde. Eu faço diferença entre saudade e nostalgia: saudade é exatamente a falta da presença. Saudade era a falta da minha rua, a falta das esquinas brasileiras, era a falta do céu, da cor do céu, da cor do chão, o chão quando chove, o chão quando não chove, da poeira que levanta no Nordeste quando a água cai em cima da areia, do gostinho que a chuva faz brotar, do verde, do orvalho da manhã, da água morna do mar... Eu não tinha por que reprimir essa saudade. E mesmo para criar, eu precisava ter essa saudade comportada. Ela era a razão de ser para mim. Com isso a gente aprendeu uma coisa fundamental: jamais transformar a saudade numa enfermidade que nos acabasse. (FREIRE, 1984)

Em seu discurso, Paulo Freire auxilia no vislumbramento das duas distinções fundamentais entre nostalgia e saudade. Por um lado, ele fala no caráter de "enfermidade" da primeira, bem como no seu corrente emprego para tratar o sentimento do exilado; por outro, a sua tentativa era justamente a de amenizar o lado patológico deste afeto e convertê-lo em saudade: esta sim dirigida a objetos-valor específicos e pontuais - como a "rua", as "esquinas" e o "céu" de sua cidade nordestina. Ele classifica ainda a "saudade comportada" como uma paixão capaz de fazê-lo criar, uma "razão de ser" e, portanto, desprovida da carga negativa da nostalgia - "uma enfermidade que nos acaba".

Como a abordagem do léxico é cultural (GREIMAS, 1983), não se pode deixar de citar que o termo "saudade", na extensão de seus significados, só ocorre na língua portuguesa. Os sentimentos relacionados à falta, em outros idiomas, em geral não ocorrem como nomes (substantivos), mas por meio de verbos, locuções verbais ou outras palavras cujo sentido é apreendido por aproximação. Em espanhol/castelhano pode-se dizer te extraño; em francês, j'ai regret; em alemão, ich vermisse dish - todas expressões verbais. Em inglês, há tentativas como a palavra homesickness, relacionada à falta de casa ou do país, ou ainda longing e to miss, utilizadas quando se sente a ausência de uma pessoa. Na diferenciação que estamos traçando, homesickness está mais relacionada à nostalgia do que à saudade, visto que se trata da falta de todo um contexto do qual se está distante.

Em 2004, pesquisa realizada por uma empresa britânica com mil tradutores classificou o termo "saudade" do português como a sétima palavra mais difícil de ser traduzida dentre expressões de todas as línguas. "Segundo a diretora da Today Translations [responsável pela pesquisa], Jurga Ziliskiene [...] o problema para o tradutor é refletir, com outras palavras, as referências à cultura local que os vocábulos originais carregam" (BBC, 2004). 
Obviamente, os afetos da saudade e da nostalgia são universais - marcam a existência do ser humano na dimensão do tempo e do espaço. Ainda que o termo específico seja da língua portuguesa, as evidências patêmicas da falta mostram-se tematizadas e figurativizadas nos mais variados textos e é dos temas prediletos da literatura.

$\mathrm{Na}$ busca por distâncias e aproximações entre as duas paixões, um caminho esclarecedor é vasculhar as etimologias. Embora não haja unanimidade sobre as origens de saudade, ela parece ter derivado do latim "solitate" (=solidão), o que produziu variantes no português arcaico como "soedade", "soidade" "suidade". Até a sua configuração atual, a palavra pode ter sofrido influência de outras terminologias, como explica Silva (2002, p.412):

Em árabe, as expressões suad, saúda e suidá significam sangue pisado e preto dentro do coração, além de serem metáforas de profunda tristeza. A as-saudá, uma doença do fígado entre os árabes, é diagnosticada pela melancolia do paciente. Pode ter havido mistura de várias procedências para consolidar o vocábulo, além de mescla do verbo saudar.

Afora a questionável relação com o árabe, Ferreira (2004) cita que a etimologia da palavra saudade seria o termo latino solitate "possivelmente com influência de saúde" (grifo nosso). A referência à "saúde", em questão, seria um justo diferenciador para a configuração de nostalgia, esta sim definida por seu caráter patológico, doentio.

A origem desta última paixão, que ocorre em vários idiomas, aliás, já é mais convencionada. Nostalgia vem do grego nostos (=regresso) e algos (=dor). A palavra teria sido cunhada pelo suíço Johannes Hofer (1669-1752) em um trabalho médico datada de 1688. "Sua tese descrevia uma enfermidade da qual foi acometido um estudante e um empregado. Estes agonizavam, mas quando regressaram para suas casas, com suas famílias, se recuperaram milagrosamente" (ETIMOLOGÍA, 2011, tradução nossa). ${ }^{3}$

Em suma, quando saudade e nostalgia não são tomadas como sinônimos, em sentido genérico, pode-se estabelecer diferenças bem pontuais quanto às causas e consequências relacionadas às duas paixões. Tais distinções, muitas vezes, são ignoradas no momento da discursivização de incursões modais que acabam por determinar o sentimento de falta, de vazio e de ausência.

O léxico "saudade" é infinitamente mais empregado na língua portuguesa pela vasta abrangência de sua acepção na cultura. Tais fatos e especificidades são de grande interesse na semiótica, porque são reveladores das diferentes transformações que podem operar-se no sujeito. Passemos, agora, à verificação de como as duas paixões originam-se nos níveis fundamental e narrativo.

\section{UMA VISÃO SEMIÓTICA DA FALTA}

Para a semiótica, as paixões perpassam a maioria dos textos, tendo em vista que elas são motores de todas as ações humanas e que a enunciação nada mais é que transformar em discurso a subjetividade do enunciador. Saudade e nostalgia são componentes naturais e frequentes da existência. Isto porque o ser humano está submetido ao jogo do acaso, que aproxima e afasta pessoas, objetos e contextos a que se tem afeição ao longo de seu percurso pelo mundo. É natural, portanto, que tais paixões percorram os textos, estando

\footnotetext{
3“Su tesis describía una enfermedad que sufrieron um estudiante y um sirviente. Estos agonizaban, pero cuando regresaran a su casa com su familia se recuperaron milagrosamente”.
}

Disponível em: http://seer.fclar.unesp.br/casa 
evidentes no nível discursivo ou ainda vindo à tona só a partir de constatações modais no nível narrativo e fundamental.

Tais afetos relacionam-se diretamente à falta de algo que existiu e que preenche o sujeito de um vazio e, concomitantemente, do desejo de vivenciar novamente a presença. Trata-se, portanto, do que a semiótica chama de "estados de alma", que passou a ser também objeto de seus estudos - para além dos "estados de coisas".

"A organização da intersubjetividade é articulada por meio de estruturas polêmicas e contratuais" (FIORIN, 2007a, p. 2). Ora, se existe a discursivização da falta, significa que, anteriormente, o sujeito esteve em conjunção com um objeto-valor e não mais o tem - esta é a característica semiótica básica da saudade e da nostalgia. Além disso, pode haver uma relação fiduciária que teve de ser rompida - o que é essencial é que o objeto-valor está ausente. "Há que distinguir uma falta objetal de uma falta fiduciária. Aquela é a carência do objeto que se desejava; esta é uma crise de confiança", explica Fiorin (2007b, p.15).

$\mathrm{O}$ sujeito modal envolve-se numa espera fiduciária tanto antes da paixão quanto após um possível reencontro com o objeto-valor, revestindo-o sempre de simulacros de eternidade. A saudade e a nostalgia são sempre paixões chamadas "complexas", pois são resultantes de outros percursos passionais, ou seja, a existência delas está condicionada necessariamente a um afeto prévio deflagrador de uma conjunção, agora desfeita. Segundo Bertrand (apud MARQUES E SILVA, 2008, p.2), a nostalgia "marca a persistência, na memória do sujeito, de uma conjunção terminada".

"A um ausente", poema de Carlos Drummond de Andrade, discursiviza de maneira clara a questão do afastamento do sujeito de estado com relação ao objeto-valor (disjunção) - "o não previsto nas leis da amizade e da natureza" -, bem como a quebra do contrato fiduciário - "um pacto implícito que rompeste", "detonaste o pacto" (ANDRADE, 2002, p.41).

Tenho razão de sentir saudade, tenho razão de te acusar.

Houve um pacto implícito que rompeste

E sem te despedirdes foste embora.

Detonaste o pacto.

Detonaste a vida geral, a comum aquiescência

De viver a explorar os rumos de obscuridade

Sem prazo, sem consulta, sem provocação

Até o limite das folhas caídas na hora de cair.

Antecipaste a hora.

Teu ponteiro enlouqueceu,

Enlouquecendo nossas horas.

Que poderias ter feito de mais grave

Do que o ato sem continuação, o ato em si,

$\mathrm{O}$ ato que não ousamos nem sabemos ousar

Porque depois dele não há nada?

Tenho razão para sentir saudade de ti,

De nossa convivência em falas camaradas,

Simples apertar de mãos, nem isso, voz

Modulando sílabas conhecidas e banais

Que eram sempre certeza e segurança. 
Sim, tenho saudades.

Sim, acuso-te porque fizeste

O não previsto nas leis da amizade e da natureza,

Nem nos deixaste sequer o direito de indagar

Porque o fizeste

Porque te foste.

As manifestações passionais resultam das transformações, ou modalizações, do sujeito de estado. Isso significa que a saudade e a nostalgia serão determinadas por certos caminhos percorridos no nível narrativo da enunciação envolvendo a possibilidade (ou não) do indivíduo querer, dever, saber e poder (modalidades básicas) conjugadas com o ser e o fazer (dependendo se o percurso é mais subjetivo ou objetivo, respectivamente). Tais combinações são chamadas "arranjos sintagmáticos".

"Para descrever, com precisão, o afeto de que nos ocupamos é preciso ver como se dispõem as modalizações que o definem" (FIORIN, 2007b, p.14). O sujeito saudoso e nostálgico é aquele que "quer estar conjunto" com o objeto-valor, mas "não pode" por alguma circunstância.

Estas paixões envolvem sujeitos de dois tipos: "atualizados" ou "realizados". Falamos deste quando a falta é uma condição permanente e eterna, e o sujeito vive apenas das recordações de algo que nunca mais estará em conjunção com ele; isso ocorre, em muitos casos, com a nostalgia, pois o exilado, ou o adulto que lembra a infância, não guarda esperanças de regresso ao objeto-valor. Em outros casos, a saudade está relacionada a um sujeito atualizado, pois é paixão que pode ter um fim, caso ele entre novamente em conjunção com o motivo de sua falta.

No processo de enunciação que envolve a saudade e a nostalgia percebe-se, com frequência, a utilização da debreagem enunciva para a criação de efeitos de distanciamento. Assim, a referência ao objeto-valor ("ele/ela") se faz sempre num espaço que é do "lá" e num tempo que é de "então". Ocasionalmente, para a materialização do abismo que há entre sujeito e objeto-valor, ao lado da debreagem enunciva, lança-se mão da debreagem enunciativa, com a qual se empenha um eu/aqui/agora como contexto do estado disfórico do sujeito.

Quanto à aspectualização, as duas paixões aqui estudadas podem ser "pontuais" ou "durativas", dependendo do caso de disjunção e da possibilidade de uma nova conjunção entre sujeito e objeto-valor. Em geral, como a nostalgia relaciona-se a um contexto perdido, há mais possibilidade de que ela seja durativa. Sobre a temporalização, tanto saudade quanto nostalgia voltam-se para um passado, quando havia a conjunção entre as duas instâncias e, portanto, o estado era de euforia. $\mathrm{O}$ afastamento do objeto do sujeito de estado, na medida em que provoca a disforia, traz consigo os impasses modais de "querer estar conjunto" e "não poder", que se refletem no discurso patemizado.

\section{Um show para cantar o fim do exílio}

Veloso (2005, p.138), em artigo publicado no Pasquim, em 26 de fevereiro de 1970, dava a sua impressão sobre o retrato musical possível daquela década:

O som dos 70 certamente só será audível quando nós estivermos perto dos 80 . Pelo menos só então será identificável. Talvez, pelo contrário, seja ouvido de pronto e fique para sempre inidentificável. O 
som dos 70 talvez não seja um som musical. De qualquer forma, o único medo é que essa venha a ser a década do silêncio.

O exílio e a fuga de grande parte dos intelectuais que faziam música após o AI5, no final de 1968, fez com que a década de 70 desse seus primeiros passos no silêncio. A repressão e o medo tornaram o Brasil uma nação histérica e sem voz. Era o retrato fiel da canção Rosa dos ventos, de Chico Buarque: do medo criava-se o trágico; em cada rosto pintava-se o pálido, e nenhuma lágrima poderia rolar, nenhuma lástima para socorrer.

Os versos são também o mote do espetáculo homônimo que rompeu o tal silêncio do país. O ano era 1971. Maria Bethânia mantinha-se como foco de resistência num Brasil que via seus principais intelectuais e artistas partirem - para o degredo, para a prisão, para a morte. Mais especificamente, Rosa dos ventos foi concebido para cantar a volta de Caetano Veloso e Gilberto Gil, exilados em Londres desde 1969; para entoar, de modo genérico, as saudades e nostalgias dos que ficaram e dos que se foram.

Num jorro cênico nunca antes visto, a intérprete desfila um repertório elaborado com composições brasileiras novas e antigas, textos de Fernando Pessoa e Clarice Lispector, canções tradicionais e cantigas de roda da Bahia. Sob a direção de Fauzi Arap, a intérprete faz, sobretudo, teatro: canções transmutavam-se em textos dramáticos; figurinos e cenários alternavam-se por entre os blocos; cada gesto proporciona uma multiplicidade de sentidos.

Para além dos elementos políticos, o formato primoroso do "show encantado" (como foi chamado) provocava, naquele início da década de 70 , uma verdadeira revolução estética no conceito de espetáculo musical. O teatro estava a serviço da música, e, assim, Bethânia conduzia o público por uma narrativa construída por poemas e canções em diálogo constante.

Nas palavras de Caetano Veloso, "o show Rosa dos ventos é um marco na história dos espetáculos de música no Brasil, sendo o mais bem-sucedido desse gênero exclusivamente brasileiro que é o show de longa temporada com um artista solo, feito de canções e textos, com belas imagens teatrais, a que se assiste como a um grande filme de arte" (VELOSO, 1997, p.456).

Em linhas gerais, Bethânia mostrava, nos textos e canções, seu amor à pátria, o medo do regime, o chamado pela mobilização popular, a saudade/nostalgia pelo passado do país e por seu passado pessoal (infância). Falava poeticamente do verdadeiro brasileiro, do homem forte que sai do sertão altercando uma luta diária nas cidades. Lembrava mitos indígenas, cantigas de roda, pontos de Candomblé, lendas formadoras cristãs. Entoava clássicos em espanhol e criava uma espécie de retrato multifacetado de um Brasil sofrido e resistente.

Ela cantava as tristezas dos pescadores que nunca sabem se voltam do mar, bem como a lembrança de marinheiros errantes e a esperança dos que lhes esperam. Bethânia trazia textos e canções enigmáticas, de forte carga pessimista e dramática, ao mesmo tempo em que corria no palco ao som de músicas carnavalescas. Um espetáculo riquíssimo em metáforas, em alegorias e em simbologias.

$\mathrm{O}$ roteiro, baseado nas cinco partes da mandala de Jung, era dividido em $1^{\circ}$ e $2^{\circ}$ atos, obedecendo a uma sequência rigorosa. $\mathrm{O} 1^{\circ}$ ato contava com um prólogo, seguido dos blocos Terra, Água e Eu-difícil. O $2^{\circ}$ ato era composto de Fogo e Ar, encerrando com um Finale.

Cada um dos elementos naturais representados possuía um figurino específico desenhado por Flávio Império. O cenário era simples, composto de uma rampa forrada de 
tecido preto que subia até parte das paredes; em cada lado do palco abriam-se espaços disformes onde eram projetados slides com fotos de Bethânia interagindo com o elemento natural de cada bloco.

Foi utilizando-se das características dos diferentes elementos naturais que o diretor conseguiu evidenciar, no show, todas as faces de Maria Bethânia. Sua interpretação materializa, no enunciado cênico e linguístico, as mais variadas paixões, que vão da calma da água à energia do fogo. Os sentimentos de saudade e nostalgia perpassam todo o roteiro em vista do objetivo principal do show - evocar reflexões sobre parentes e amigos que estavam indo embora pela força militar e lembrar que a vida também está em constante marcha e transformação. Os desdobramentos das diferentes paixões ligadas à terra, água, fogo e ar tornam Rosa dos ventos um objeto praticamente inesgotável para a análise semiótica.

\section{Percursos da lembrança em Rosa dos ventos}

Ao longo de quase uma hora e meia, agregando as mais diversas manifestações artísticas na composição do espetáculo, Rosa dos ventos fornecia ao enunciatário grande quantidade de signos cuja leitura e interpretação estavam condicionadas àquele momento histórico. Devido à natureza deste artigo, optamos por analisar alguns versos bem pontuais relacionados à saudade e à nostalgia. O objetivo aqui não é dissecar toda a estrutura do show ou trilhar todos os percursos narrativos, mas exemplificar como se dão esses dois tipos de configurações passionais em determinados pontos do espetáculo.

De modo genérico, pode-se dizer que temas influenciados pela saudade e nostalgia são recobertos por figuras ao longo de todo o evento artístico. Basicamente, a partir da conceituação dos léxicos que já fizemos, pode-se considerar que a saudade, mais genérica, é paixão presente nos que ficam, nos que se despedem de seus amigos e parentes exilados para além de um mar da memória que perpassa o show. A nostalgia manifesta-se nos que se vão, nos que estão distantes da pátria e, portanto, sentem falta de todo um contexto, de toda uma vida perdida de modo sempre melancólico.

Vamos começar com uma das canções integrantes do bloco da Terra - Pai Grande, de Milton Nascimento:

Pai Grande (Milton Nascimento)

Meu pai grande

Inda me lembro

E que saudade de você

Dizendo: eu já criei seu pai

Hoje vou criar você

Inda tenho muita vida pra viver

Meu pai grande

Quisera eu ter sua raça pra contar

A história dos guerreiros

Trazidos lá do longe

Trazidos lá do longe

Sem sua paz

De minha saudade vem você contar

De onde eu vim

É bom lembrar

Todo homem de verdade

Era forte e sem maldade 
CASA, Vol.10 n.1, julho de 2012

\author{
Podia amar \\ Podia ver \\ Todo filho seu \\ Seguindo os passos \\ E um cantinho pra morrer \\ Pra onde eu vim \\ Não vou chorar \\ Já não quero ir mais embora \\ Minha gente é essa agora \\ Se estou aqui \\ Trouxe de lá \\ Um amor tão longe de mentiras \\ Quero a quem quiser me amar. \\ (NASCIMENTO, 2011)
}

Há, claramente, a separação de duas instâncias: um personagem principal, também narrador em primeira pessoa, e outro personagem que tem, com o primeiro, uma relação familiar. O sentimento passional da falta aparece, desde o início, nos versos "Inda me lembro / e que saudade de você", que evidenciam a disjunção, ocorrida há muito tempo, entre dois sujeitos ( $\mathrm{S} 1$, o narrador, e $\mathrm{S} 2$ ), podendo $\mathrm{S} 2$ ser entendido como objeto-valor do primeiro na modulação da falta. Logo percebemos que se trata de um neto (S1) e de um avô (S2), pois a expressão "pai grande" faz uma referência ao termo em inglês grandfather (=avô; traduzido literalmente como "pai grande"), além do discurso "eu já criei seu pai / hoje vou criar você", colocado diretamente na voz de S2.

"Inda tenho muita vida pra viver", igualmente enunciado pelo avô, ganha dois sentidos. Primeiramente a questão da continuidade da tradição e da "raça" deste homem "de verdade", "forte" e "sem maldade", haja vista que é o avô quem deseja criar (entendido como educar) filho e neto. Por outro lado, a mesma expressão, que revela a certeza da longevidade daquele homem, entra em contradição com a inexistência dele no momento da enunciação, o que pode sugerir a sua ausência ou a sua morte - um possível detonador da disjunção entre sujeito (S1) e objeto-valor (S2).

A figura dos "guerreiros" reveste temas relacionados à força e à veemência dos homens do passado - da mesma linhagem do avô -, mas "sem sua paz", ou seja, homens de combate por seus ideais. Nota-se debreagem enunciva nos versos "trazidos lá do longe": falase de um eles, lá no longe, e colocados num tempo passado. Cria-se um efeito de distanciamento que contribui na enunciação da imensa falta sentida do avô e dos homens benevolentes. S1, por sua vez, coloca-se num tempo presente, numa terra próxima (aqui) e confundindo-se com o próprio narrador, o que indica debreagem enunciativa e, da conjugação dos dois efeitos, a revelação da disjunção.

Para o contexto atual, o sujeito de estado traz as recordações e a persistência daquele lugar/tempo em que "todo homem de verdade / era forte e sem maldade". Se, então, ele "podia amar", por dedução infere-se que no aqui/agora já não se pode contar com tal sentimento. Também já não se pode ver "todo filho seu / seguindo os passos / e um cantinho pra morrer", ou seja, no contexto em que o discurso é enunciado já não se segue a tradição e os bons exemplos do passado, o que revela uma inversão de valores.

Há um percurso gradual, ao longo do enunciado, em que o sujeito modal/narrador começa com a lembrança e termina referindo-se completamente ao seu estágio de vida atualizado. Ao longo desse caminho, ele também se atualiza, "já não quero ir mais embora / minha gente é essa agora". Os últimos versos do enunciado estão no aqui e 
agora. Neste ponto, temos pistas suficientes para dizer que a paixão expressa, no caso, é a saudade - retomando a conceituação do léxico que fizemos inicialmente.

Além de tratar-se de um sujeito atualizado (traço da saudade), há uma esperança renovadora no sujeito de estado, que o levará a novas atualizações e, provavelmente, a uma extinção da disforia. O sujeito está disposto a reavivar as heranças de caráter deixadas pelo avô ("um amor tão longe de mentiras") e semear em outros sujeitos o mesmo sentimento benévolo ("quero a quem quiser me amar"). A baixa disforia do sujeito, reveladora do sentimento de saudade e de certo contentamento por dar continuidade ao caráter da família, mostra-se em "Pra onde eu vim / não vou chorar" que, se não aponta para a alegria (euforia completa), revela o apaziguamento da tristeza. Tal configuração não aconteceria na nostalgia, sempre recoberta de forte carga melancólica.

A oposição semântica fundamental que se depreende desses versos é o "caráter $\mathrm{X}$ truculência". O primeiro desdobrado pela herança deixada pela ancestralidade do enunciador e a segunda depreendida a partir das colocações textuais inseridas no contexto da ditadura militar.

Bethânia canta um brasileiro do passado, um pai grande. É ele quem carrega o caráter e a decência que se pode esperar de um homem e, pela inexistência de seus pares em um tempo dominado por repressores sem dignidade, nasce a saudade - também entendida como uma hipervalorização do passado e uma descrença no presente. A figura dos netos deseja, metaforicamente, ver a raça do avô refletida nos novos tempos.

No bloco da Terra, a intérprete evoca o nordeste, o sertanejo que é, antes de mais nada, um forte (como diria Euclides da Cunha). Também relembra o índio (verdadeiro brasileiro): apaixonado, ávido, puro. Relembra a infância, quando a inocência não deixava sentir as dores do mundo. A lembrança, no Primeiro Ato, serve, concomitantemente, como saudade do passado e como exemplo ético para o presente maculado e sujo pela desonra da ditadura. Guiraud (1981, p.96) afirma que essa é também uma característica da mensagem estética: "[os sistemas estéticos] significam os nossos desejos ao recriarem um mundo e uma sociedade imaginários - arcaico ou futurista - que compensam a repressão e as frustrações do mundo e da sociedade existentes."

Do $2^{\circ}$ Ato, extraímos outro exemplo. Trata-se da conjugação da música Minha história, versão de Chico Buarque para a italiana Gesubambino, com Lembranças, de Raul Sampaio e Benil Santos. Ambas integram o bloco do Fogo:

\section{Minha história (Chico Buarque)}

Ele vinha sem muita conversa, sem muito explicar

Eu só sei que falava e cheirava e gostava de mar

Sei que tinha tatuagem no braço e dourado no dente

E minha mãe se entregou a esse homem perdidamente, laiá, laiá,laiá, laiá

Ele, assim como veio, partiu, não se sabe pra onde

E deixou minha mãe com o olhar cada dia mais longe

Esperando, parada, pregada na pedra do porto

Com seu único velho vestido, cada dia mais curto, laiá, laiá,laiá, laiá

Quando enfim eu nasci, minha mãe embrulhou-me num manto

Me vestiu como se eu fosse assim uma espécie de santo

E por não se lembrar de acalantos, a pobre mulher

Me ninava cantando cantigas de cabaré

(BUARQUE, 1970)

Lembranças (Benil Santos e Raul Sampaio)

Lembro um olhar, lembro um lugar

Disponível em: http://seer.fclar.unesp.br/casa 
CASA, Vol.10 n.1, julho de 2012

Teu vulto amado

Lembro um sorriso, um paraíso,

que tive a seu lado

lembro a saudade, que hoje invade os dias meus

para o meu mal

lembro, afinal, um triste adeus

Sou agora no mar dessa vida um barco a vagar

Onde está seu olhar, onde está seu sorriso e aquele lugar?

Eu devia sorrir, eu devia

para meu perecer ocultar

Mas diante de tantas lembranças

me ponho a chorar

(SAMPAIO; SANTOS, 1963)

\section{Minha História (cont. Chico Buarque)}

Minha mãe não tardou alertar toda a vizinhança

A mostrar que ali estava bem mais que uma simples criança

E não sei bem se por ironia ou se por amor

Resolveu me chamar com o nome do Nosso Senhor, laiá, laiá, laiá,laiá

Minha história e esse nome que ainda hoje carrego comigo

Quando vou bar em bar, viro a mesa, berro, bebo e brigo

Os ladrões e as amantes, meus colegas de copo e de cruz

Me conhecem só pelo meu nome de menino Jesus, laiá, laiá

(BUARQUE, 1970)

As duas canções justapostas evocam um sentimento de falta. No enunciado de Minha história, o narrador e personagem, sujeito de estado, faz um relato no qual transmite todos os sentimentos de sua mãe, abandonada por seu pai que se ausentou repentinamente. É ela, enquanto sujeito da ação, que nos interessa para a análise patêmica.

O sentimento da falta ocorre pela disjunção entre a mulher e um objeto-valor, entendido aqui como a figura do marinheiro andante: esse homem misterioso que "vinha sem muita conversa, sem muito explicar" e que "falava e cheirava e gostava de mar". Pistas como "tatuagem no braço" e "dourado no dente" apontam para um estereótipo do marinheiro na cultura. O mistério e a sedução do homem funcionam como elementos de manipulação em nível narrativo.

O enunciado, antes de trazer propriamente o sentimento da falta, descreve, pela voz do sujeito de estado, o encontro, ou seja, a conjunção entre os dois genitores - "minha mãe se entregou a esse homem perdidamente". Mas, tão logo a paixão consuma-se, o homem parte "não se sabe pra onde". A indefinição desse lugar distante, situado num passado, aumenta o efeito da paixão relacionada à ausência - uma debreagem enunciva.

Após a realização da performance, que veio a gerar o filho que dá voz ao enunciado, houve a disjunção. Por um "querer estar conjunto" e um "não poder estar conjunto" do sujeito mãe com o objeto-valor marinheiro, nasce a paixão da falta. Neste caso, houve a quebra do contrato fiduciário e uma subversão da ordem deôntica, pois o homem abandonou mulher e filho. Logo, a espera do sujeito é fiduciária. A eterna espera da mulher "com o olhar cada dia mais longe", "parada, pregada na pedra do porto", sugere a melancolia atrelada ao afeto. Este é o principal argumento para que, agora, falemos em nostalgia.

O "único velho vestido, cada dia mais curto", uma figura que tematiza a prostituição a que teve de se entregar a mulher, funciona como sanção negativa do percurso. 
Outra figura que reforça o destino desse sujeito é o fato de "não se lembrar de acalantos" para ninar o filho, e a substituição daqueles por "cantigas de cabaré".

Neste ponto, a canção Lembranças, entendida como a música entoada para fazer dormir o filho, vem trazer para o discurso a voz do sujeito da ação. É a mãe, agora, quem descreve a sua nostalgia.

É importante observar como o sentimento de falta não é dirigido, mas pulverizado em todo um contexto que abrange não só a pessoa amada, mas um local, um tempo e diversos fatos - característica da nostalgia: "lembro um olhar, lembro um lugar / teu vulto amado", "um sorriso", "um paraíso", "um triste adeus". A melancolia da despedida, aliás, aparece mais uma vez quando o sujeito vale-se da metáfora "sou agora no mar dessa vida um barco a vagar". Ao contrário do sujeito da canção Pai Grande, que não chora em sua saudade, a mãe conclui a cantiga pondo-se a chorar de nostalgia.

Podemos identificar a natureza da paixão da falta em questão como nostalgia pelas características do léxico, que elencamos inicialmente. É notório e sintomático que o enunciador fale, textualmente, entretanto, em "lembro a saudade, que hoje invade os dias meus". A saudade, como já foi dito, é o vocábulo mais genérico e predileto, na língua portuguesa, para designar a falta. Temos aqui um sujeito com pouca possibilidade de atualização e, portanto, realizado, como em geral acontece na nostalgia.

Findo o percurso narrativo da mãe, no enunciado, é o filho/narrador que assume o papel de sujeito da ação. Ele se distancia do passado por debreagem enunciativa, ganha o presente e passa agora a discursivizar o seu próprio destino rebelde. É como se, afinal, ele assumisse um papel também boêmio, como o ocupado inicialmente pelo pai. Afinal, quando vai, de bar em bar, vira a mesa, berra, bebe e briga. Quanto ao nome "Jesus", que o sujeito da ação lhe confere, há a possibilidade de ler o percurso da mãe em analogia com a história bíblica. Nossa Senhora, afinal, tem um filho concebido pelo mistério de um Deus que também parte repentinamente após a anunciação do anjo.

A canção constrói um Jesus rebelde, ninado por canções de cabaré, criado sem a presença do pai. Faz-se aqui a história de um Jesus terreno, que tem como calvário a própria existência. Seu sofrimento é como aquele do Deus pregado à cruz, somado à falta de estrutura familiar, humana, espiritual que o impede de encontrar o caminho da salvação.

O pai que parte para o mar abandonando a mãe apaixonada é uma alegoria para todos os exilados ou mortos pelo regime militar. A situação descrita remete às milhares de mulheres, homens, pais, mães, filhos que ficaram, metaforicamente, no porto a olhar para o mar, à espera dos seus expatriados. A expressão "pregada", utilizada para descrever a situação da mulher, remete a Jesus pregado na cruz, a seu sofrimento, sua condenação injusta.

As metáforas, compreendidas por mecanismos de isotopia, eram recursos utilizados, naquele momento, para se transmitir uma mensagem estética cujas significações de protesto deveriam chegar ao público e ludibriar as forças censoras. A trajetória de Rosa dos ventos por quase dois anos, passando pelas principais capitais do Brasil, mostra a eficácia de tais mecanismos de enunciação.

\section{Conclusão}

Saudade e nostalgia são, afinal, paixões que - embora vistas genericamente como sinonímicas e com configurações modais parecidas - possuem características próprias. A primeira, nem sempre de elevada carga disfórica, serve para designar todo tipo de falta ocasionada pela lembrança. Já a nostalgia, entendida como um tipo de saudade, tem como causa a abrangência de todo um contexto congelado no tempo ou no espaço, uma vida perdida 
ou de difícil acesso - o que a faz ser a paixão específica para designar o sentimento dos exilados e degredados. A nostalgia sempre estará atrelada a outras paixões disfóricas, como a melancolia e a tristeza mais profunda.

Em Rosa dos ventos, o contexto da ditadura militar propicia a leitura da saudade e da nostalgia como manifestações da indisposição com o presente maculado pela dor, bem como o reflexo do abismo que o exílio e a morte cavaram entre pessoas queridas.

\section{REFERÊNCIAS}

ANDRADE, Carlos Drummond de. Farewell. 7 ed. Rio de Janeiro: Record, 2002.

O avesso das coisas. 2 ed. Rio de Janeiro: Record, 1987.

ASSIS, Machado. Esaú e Jacó. 12 ed. São Paulo: Ática, 2002.

BBC. Saudade “é a $7^{\text {a }}$ palavra mais difícil de traduzir". Jun. 2004. Disponível em: http://www1.folha.uol.com.br/folha/bbc/ult272u398210.shtml. Acesso em: 2 jul. 2011.

BUARQUE, Chico. Minha história (versão de Dalla / Palotino). 1970. Disponível em: $<$ http://www.chicobuarque.com.br/construcao/mestre.asp?pg=minhahis_70.htm>. Acesso em 10 jul. 2011.

ETIMOLOGÍA de Nostalgia. Disponível em: http://etimologias.dechile.net/?nostalgia. Acesso em: 8 jul. 2011.

FERREIRA, Aurélio Buarque de Holanda. Novo dicionário eletrônico Aurélio de língua portuguesa. Versão 5.0. Curitiba: Positivo Informática, 2004. Software.

FIORIN, José Luiz. Paixões, afetos, emoções e sentimentos. Cadernos de semiótica aplicada, v. $5, \quad$ n. $2, \quad$ dez. 2007a. Disponível em: http://www.felar.unesp.br/grupos/casa/CASA-home.html. Acesso em: 15 jul. 2011.

Semiótica das paixões: o ressentimento. Alfa (ILCSE/UNESP), v. 51, p. 9-22, 2007b.

FONTANILLE, Jacques; GREIMAS, Algirdas Julien. Semiótica das paixões: dos estados de coisas aos estados de alma. São Paulo: Editora Ática, 1993.

FREIRE, Paulo. Intuição e fantasia para a educação de todos. Lua nova: revista de cultura e política, São Paulo, v. 1, n. 3, dez. 1984. Disponível em: http://www.scielo.br/scielo.php?pid=S0102-64451984000300009\&script=sci_arttext. Acesso em: 29 jun. 2011.

GREIMAS, A. J. Du sens II: essais sémiotiques. Paris: Seuil, 1983.

GUIRAUD, Pierre. A semiologia. 2. ed. Lisboa: Editorial Presença, 1981.

HOUAISS, Antônio. Houaiss eletrônico. Versão monousuário 3.0. São Paulo: Objetiva, 2009. Software.

LISPECTOR, Clarice. A hora da estrela. Rio de Janeiro: Rocco, 2006.

MARQUES E SILVA, Lílian Maria. Aspectos distintos da paixão da nostalgia na construção dos sujeitos dos enunciados nas canções de Nando Reis. Estudos semióticos. n. 4, 2008. Disponível em: http://www.fflch.usp.br/dl/semiotica/es. Acesso em: 8 jul. 2011. 
MICHAELIS - Moderno dicionário da língua portuguesa. [S.1.]: Melhoramentos, 2009. Disponível em: http://michaelis.uol.com.br/. Acesso em: 28 jun. 2011.

NASCIMENTO, Milton. Pai grande. 1969. Disponível em: http://www.miltonnascimento.com.br/\#/obra. Acesso em: 10 jul. 2011.

SAMPAIO, Raul; SANTOS, Benil. Lembranças. 1963. Disponível em: http://www.paixaoeromance.com/60decada/lembrancas/h_lembrancas.htm. Acesso em: 10 jul. 2011.

SILVA, Deonísio da. A vida íntima das palavras: origens e curiosidades da língua portuguesa. São Paulo: Arx, 2002.

SILVESTRE, Osvaldo Manuel. Saudade ou nostalgia. 2008. Disponível em: http://ardotempo.blogs.sapo.pt/22796.html. Acesso em: 29 jun. 2011.

VELOSO, Caetano. O mundo não é chato. São Paulo: Companhia das Letras, 2005. Verdade tropical. São Paulo: Companhia das Letras, 1997. 